\title{
Migración internacional legal desde la frontera norte de México
}

\section{Gabriel Estrella Valenzuela*}

En este trabajo se evalúa un efecto "no previsto" que generó en México la Ley Simpson-Rodino de 1986; la ampliación del grupo laboral internacional legal mexicano conocido como commuters. Para analizar los cambios que generó la réforma legal sobre este grupo (caracterizado porque sus integrantes residen en las localidades fronterizas del norte de México y laboran cotidiana y legalmente en Estados Unidos de América) en términos del número de integrantes, de su composición por edad, sexo, escolaridad, estructura familiar y localidad de residencia, se utiliza la información generada para Baja California por las Encuestas Demográficas de 1986 y 1990.

A partir de esa información y utilizando modelos de regresión Logito en los que se incluyen variables relativas a las características tanto de los individuos como de sus grupos domésticos y del contexto en el que se ubican, se genera evidencia estadística que apoya las proposiciones de que: i) se amplió el espectro de los estratos sociales que recurren a esta modalidad de migración; ii) para los grupos de nuevo ingreso las características de selectividad perfilan una estrategia de reproducción orientada a la movilidad ascendente, y iii) los factores contextuales generaron una redistribución geográfica del grupo de commuters en Baja California.

\section{Introducción}

A más de seis años de haberse aprobado la Ley de Reforma y Control de Inmigración el 6 de noviembre de 1986 (iRCA, según sus siglas en inglés) mejor conocida como Ley Simpson-Rodino, en este trabajo ${ }^{1}$ nos proponemos efectuar la evaluación de un aspecto poco atendido de los efectos generados en México por dicha modificación legislativa.

El aspecto que nos proponemos evaluar se aleja relativamente del análisis predominante en este tópico (i.e. los flujos de indocumentados), pues centramos la atención en los grupos familiares del estado de Baja California que durante el periodo 19861990 han incluido en su estrategia de reproducción el recurso de la migración laboral internacional legal, con particular énfasis en

* Investigador Nacional, Becario de la UABC al Desempeño Académico, Instituto de Investigaciones Sociales de la Universidad Autónoma de Baja California.

1 Este trabajo está basado en el informe terminal del proyecto de investigación "Grupo doméstico, crisis y migración internacional", financiado por la Asociación Mexicana de Población, A.C. y reportado en G. Estrella (1992). 
los grupos en los que uno o más de sus miembros -aprovechando la oportunidad ofrecida por las reformas a la legislación migratoria- han pasado a formar parte del flujo laboral usualmente denominado commuters.

En el caso del estado de Baja California, así como a lo largo de toda la frontera entre México y Estados Unidos de América (EUA), el movimiento de fuerza de trabajo mexicana que tiene su residencia en las ciudades localizadas en el lado mexicano de la frontera internacional y que cotidianamente cruza la frontera (la gran mayoría a diario) de forma legal para desempeñar labores en las actividades productivas de las ciudades o áreas agrícolas en territorio de Estados Unidos, no es un fenómeno reciente.

Sin embargo, como trataremos de mostrar, la forma acentuada con la que se presentó la crisis de los ochenta en la frontera norte de México, parece haber generado, en principio, una ampliación de los estratos sociales que ahora recurren a esa forma de migración internacional.

En esta zona fronteriza del norte del país, la "década perdida" no sólo representó un estancamiento $\mathrm{y}(\mathrm{o})$ decrecimiento en sus niveles absolutos de desarrollo económico como en el resto de México, sino que además significó un retroceso en sus niveles relativos de desarrollo en comparación con los de otras áreas del país.

En efecto, en esta zona del país las políticas de contención del salario, de recortes a la inversión pública y la redistribución del ingreso que generó el proceso inflacionario, se conjugaron con los efectos "instantáneos" que generan en la frontera norte de México las sucesivas devaluaciones del peso frente al dólar desde 1976 hasta la fecha, para estructurar un contexto coyuntural que resultó extremadamente propicio para que -a partir de 1986- la población de Baja California aprovechara el recurso de la migración internacional legal que propició la aprobación de las enmiendas a la legislación de inmigración de Estados Unidos mediante la Ley Simpson-Rodino.

En consecuencia, nos hemos propuesto como objetivo central del trabajo que se presenta a continuación, el dar respuesta, entre otras, a las siguientes interrogantes básicas: ¿Cuál es el perfil sociodemográfico de los miembros de los hogares que ahora participan en el fenómeno de los commuters? ¿De qué magnitud son los cambios cuantitativos y cualitativos que esa coyuntura generó en el grupo laboral de los commuters, y cuáles son las características predominantes en los hogares que ahora recurren a la migración laboral internacional? 


\section{Grupos domésticos y migración internacional}

La familia, el hogar o el grupo doméstico son conceptos a los que se ha recurrido como unidades de análisis en la literatura sociodemográfica desde diversas perspectivas. En este sentido, se han identificado al menos tres líneas de investigación en las que el grupo doméstico desempeña un papel relevante, al constituirse total o parcialmente en unidad de análisis (García et al., 1982).

La primera vertiente de este tipo de análisis es la que se define a partir del estudio de la participación femenina en las actividades económicamente productivas u otro tipo de comportamientos demográficos (e.g. fecundidad, uso de anticoncepción), incorporando características del contexto familiar de los individuos -composición de parentesco, tamaño del hogar- como factores determinantes de la forma en que dichos individuos se comportan.

Una segunda línea de investigación, en la que el grupo doméstico o el hogar son asumidos como unidades analíticas, es la correspondiente a los trabajos relacionados con la demografía de la familia. A través de estos estudios se han logrado identificar algunos elementos clave en la explicación de las variaciones en la composición de parentesco y tamaño de los hogares, las cuales, al menos en el caso de Latinoamérica, parecen estar principalmente relacionadas con la edad, el sexo y las características socioeconómicas -tipo de localidad de residencia, estatus migratorio y ocupacional- de los jefes del hogar.

La tercera y última área de investigación en la que el hogar o el grupo doméstico constituyen el eje de análisis es la que, desde la perspectiva de los procesos de reproducción de la fuerza de trabajo, aborda el estudio de los mecanismos intra y extradomésticos a que recurren los individuos u hogares para preservar su nivel de vida en situaciones específicas. En esta línea de análisis, por una parte, se ha enfatizado el estudio del papel que desempeñan las redes sociales de relaciones entre grupos domésticos en términos de los mecanismos extradomésticos de solidaridad y reciprocidad intra e intergrupales (véase Oliveira y Salles, 1989).

A la vez, por otra parte, en el caso de los mecanismos intradomésticos a los que recurren los hogares, se han analizado los procesos referidos a la organización de las actividades del grupo doméstico en relación con patrones de comportamiento reproductivo, de división del trabajo doméstico por edad y sexo, y de la participación de sus integrantes en el mercado de trabajo. Es decir que, a través de esta línea de análisis se ha desarrollado el concepto de "estrategias de reproducción o sobrevivencia de los hogares, unidades o grupos domésticos". 
En su nivel más general y referido a la unidad doméstica como el grupo que comparte una vivienda y articula una economía común, el concepto de reproducción de la unidad se refiere "tanto a la reproducción material de las condiciones de existencia (lo que no excluye la reproducción ampliada) como a la reproducción biológica y a las estrategias en ambas esferas" (Margulis, 1989: 191).

Las estrategias en el ámbito de la reproducción material de las condiciones de existencia (i.e. de mantenimiento o de sobrevivencia), han sido definidas como el conjunto de acciones a través de las cuales el grupo doméstico intenta "lograr el ajuste entre los recursos sociales y materiales a disposición del hogar (e.g. tierra, capital, trabajo), las necesidades de consumo de sus miembros... y las alternativas de actividades productivas" (Pessar, 1982: 349, traducción mía).

En relación con las estrategias de ajuste entre recursos disponibles y necesidades que realiza el grupo doméstico, se deben de tener presentes dos consideraciones. En primer lugar, que dichas estrategias enfrentan límites externos e internos -que son definidos tanto por las características sociodemográficas de los propios grupos (i.e. número, edad, sexo, nivel educativo de los integrantes), como por factores estructurales externos al hogar (i.e. acceso a la tierra, demanda de trabajo asalariado, segmentación de mercados laborales)-, y que dichos límites, al conjugarse, definen las posibles combinaciones de actividades productivas remuneradas y no-remuneradas, a través de las cuales el grupo doméstico accede a los bienes necesarios para su sostenimiento.

En segundo lugar se debe observar que las estrategias de reproducción material que desarrollan los grupos domésticos

necesariamente deben ser dinámicas, incluso en un ambiente socioeconómico y político estable, al menos debido a los cambios en la composición familiar en diferentes etapas del ciclo vital. En condiciones de cambio social, el hogar debe diseñar estrategias especialmente flexibles e innovadoras para que sean compatibles con las oportunidades productivas cambiantes, así como para dar respuesta a los factores estructurales que afectan la capacidad productiva de la unidad (Wood, 1982: 313, traducción mía).

Las dos características de las estrategias de reproducción material de los grupos domésticos que hemos mencionado (i.e. su dinamismo, y las condicionantes internas y externas que las delimitan), permiten subrayar el hecho de que aquéllas no constituyen fines en sí mismas, sino que se trata de medios orientados a 
la consecución de determinados fines en situaciones particulares. Dicho en otros términos, las estrategias de reproducción material que desarrollan los grupos domésticos, pueden tener propósitos diversos como son, por ejemplo, la movilidad social ascendente, el mantenimiento de los niveles de vida, y en casos extremos la sobrevivencia física de la unidad.

En función de la diversidad de dichos propósitos, entre otros factores se ha sugerido (Torrado, 1986: 84-85) que las estrategias de los grupos domésticos se aborden desde varias dimensiones conductuales que permiten catalogar las estrategias de reproducción que han sido documentadas (Wood, 1982). Una primera dimensión la integran los comportamientos relacionados con la constitución de la descendencia, y en ella se incluyen conductas relacionadas con los cambios en los patrones de fecundidad y mortalidad; otra dimensión de las estrategias es la relativa a los procesos de asignación de la fuerza de trabajo disponible, ya sea a través de modificaciones de la división sexual del trabajo dentro del hogar, de la intensificación de la producción agrícola o de la producción de artesanías u otras formas de producción doméstica; paralelamente a la anterior, se delimita la dimensión relativa a la organización del consumo familiar, en la que se incluyen actividades tales como la redistribución del consumo calórico entre los miembros del grupo; en tanto que la dimensión de las migraciones laborales agrupa a los comportamientos que promueven adecuaciones en la participación de los miembros de la unidad en el mercado de trabajo asalariado, mediante la movilidad laboral geográfica, temporal o permanente, de varios o todos los miembros del grupo doméstico.

En el contexto de ese sentido amplio de las estrategias de reproducción material, podemos ubicar la relación entre las estrategias de grupos domésticos y la migración internacional. Al respecto conviene notar que el utilizar al grupo doméstico como unidad de análisis de la movilidad de la población, permite generar un acercamiento hacia la conceptualización de la migración internacional en la que se le define como un sistema de "redes sociales entre países de origen y países de destino, que se han implantado en las instituciones económicas y sociales, en las estrategias familiares y en las expectativas individuales" de las poblaciones involucradas (Root y De Jong, 1991: 232, traducción mía).

La definición de la movilidad internacional como un proceso estructurado e institucionalizado ha sido derivada en gran medida, aunque no de manera exclusiva, de la experiencia observada en el flujo laboral de México hacia Estados Unidos. En efecto, utilizando información relativa a dicho caso, Massey (1987) sugi- 
rió y sometió a prueba las proposiciones básicas de que la migración internacional

se origina en la estructura socioeconómica de las sociedades de origen y destino; que, una vez iniciada, se forman redes de migración para apoyar la migración en forma masiva; que al volverse ampliamente accesible, las familias utilizan la migración internacional como parte de sus estrategias de sobrevivencia, recurriendo a ella durante las etapas del ciclo vital en las que la dependencia alcanza su mayor nivel; que las motivaciones individuales, las estrategias familiares y las estructuras comunitarias son alteradas por la migración, en tal forma que hacen que la migración adicional sea más probable; que aún entre los migrantes temporales hay un proceso inevitable de asentamiento en el extranjero, y que entre los que se asientan hay un proceso de migración de retorno (Massey, 1987: 1 375, traducción mía).

Para propósitos analíticos Massey ha propuesto, entonces, que el proceso de migración internacional sea dividido en cuatro fases diferentes que corresponden a eventos importantes de la historia migratoria: salida, repetición, asentamiento y retorno.

De esta forma, a partir de la conceptualización de la migración internacional como un proceso social en desarrollo, multifacético, estructurado e institucionalizado, y utilizando como eje de análisis de la movilidad de la población al grupo doméstico y a las estrategias que éste pone en operación para asegurar su reproducción material, en este trabajo buscamos establecer tanto las principales modificaciones que generó la Ley de Reforma y Control de Inmigración de Estados Unidos, de 1986 (i.e. Ley "Simpson-Rodino") sobre el contingente de grupos domésticos de la frontera norte de México que han incluido a la migración laboral internacional legal como parte de su estrategia de reproducción, como las características sociodemográficas que distinguen a estos grupos domésticos de aquellos que no utilizan esta modalidad migratoria como parte de sus estrategias.

Nos interesa destacar, específicamente, qué efectos generaron los programas de Trabajadores Agrícolas Especiales (TAE) I y II que incluía la Ley Simpson-Rodino, en la composición del conjunto de grupos domésticos del estado de Baja California que integran la comunidad laboral conocida como commuters o "transmigrantes". 2

2 Una presentación detallada de la Ley Simpson-Rodino puede verse en V. Briggs (1986); M. García y Griego y C.M. Verea (1988); E. Stoddard (1989). En relación con el grupo de commuters integrado antes de la Ley Simpson-Rodino véase Acuña (1983); T. Alegría (1990); Arámburo y Fuentes (1992). 
Esos dos programas de TAE crearon la nueva categoría inmigratoria de Extranjero Residente Temporal en Estados Unidos - la cual fue otorgada a quien demostrase haber laborado al menos 90 días por año en actividades agrícolas durante el periodo comprendido de 1984 a 1986 (i.e. TAE I), o por 90 días entre mayo de 1985 y mayo de 1986 (i.e. TAE II)- y con ello se generó la posibilidad de que se ampliara el grupo de commuters o "transmigrantes".

El grupo laboral de los commuters o "transmigrantes", está integrado por las personas económicamente activas que trabajan en un lado de la frontera y que residen en el país vecino. Constituyen, así, una manifestación de la interacción sociocultural entre dos poblaciones, a la vez que tornan explícita la política económico-migratoria que hace permeable la frontera internacional para este flujo y definen, bilateralmente, un mercado laboral internacional formalmente legal.

Dadas las interrogantes planteadas y en función de la aproximación conceptual propuesta, los tres supuestos generales que orientan este trabajo pueden ser enunciados en los siguientes términos:

a) A partir de la coyuntura generada durante 1986 por la combinación de las modificaciones de la legislación migratoria de Estados Unidos con la política de austeridad implementada por el gobierno mexicano, el espectro social de los grupos domésticos de Baja California que incluyen a la migración laboral internacional legal como parte de su estrategia de reproducción, se amplió de forma tal, que ahora incluye grupos de estratos socioeconómicos que hasta antes de esa coyuntura no incluían esa forma de migración en sus estrategias de reproducción.

b) La inclusión de grupos domésticos de estratos sociales que antes no recurrían a esa modalidad de migración, ha generado una recomposición tanto cuantitativa como cualitativa del grupo de trabajadores commuters de Baja California, puesto que es de esperarse que los efectos de selectividad por edad, sexo y relación de parentesco, estén determinados por objetivos de estrategias de reproducción orientadas a la movilidad social ascendente de los grupos domésticos de ingreso reciente.

c) También resultan previsibles modalidades diferenciales de recomposición del grupo commuter -tanto cuantitativa como cualitativamente- en función de efectos contextuales distintos originados a partir de la combinación del tipo (urbano-rural) de localidad de residencia, con las estructuras económicas que caracterizan tanto a cada uno de los cuatro municipios de la entidad, como a los dos condados colindantes con ellos en la frontera internacional entre México y Estados Unidos. 


\section{Antiguos y nuevos commuters}

En Baja California, al igual que en toda la frontera norte de México y el sur de Canadá, el fenómeno laboral de los transmigrantes o commuters no es un proceso reciente. Ese fenómeno de la transmigración (i.e. de residir en un país y tener autorización para laborar en otro por contar con la categoría migratoria de Residente Permanente Legal, en el país vecino), se originó a partir del requerimiento de obtención de visa de inmigrante -forma 1-151, 551 o Green-Card (tarjeta verde)- que estableció la Ley de Cuotas de Inmigración de 1924 de Estados Unidos.

Bajo los sistemas de cuotas y límites que han operado desde esa fecha, entre 1924 y 1964 inmigraron legalmente a Estados Unidos 920128 ciudadanos mexicanos (García y Griego y Verea, 1988: 116-117), de los cuales una proporción pasó a formar parte del contingente commuters poseedor de tarjeta verde (i.e. transmigrantes). Las dimensiones de dicho contingente han constituido uno de los puntos menos esclarecidos en relación con los tarjetas verdes commuters, debido fundamentalmente a la ausencia de una definición jurídica que permita llevar un registro independiente de este tipo de transmigrantes.

Sin embargo, para el caso de los tarjetas verdes commuters mexicanos, el Servicio de Inmigración y Naturalización de Estados Unidos (SIN) ha realizado una serie de conteos de estos trabajadores en los puertos de entrada. La primera ocasión en que se elaboró un conteo de commuters mexicanos fue en 1933, año en el que el SIN identificó 52551 commuters "intermitentes" (i. e. que cruzaban la frontera un máximo de tres veces por semana) y 29963 commuters "activos" caracterizados por cruzar la frontera cuatro o más veces por semana (North y Houston, 1976: 21).

En relación con las cuantificaciones subsecuentes, en las que se eliminó la distinción entre commuters "intermitentes" y "activos", la información presentada en el cuadro 1 permite advertir tres características relativas al volumen y distribución geográfica de los commuters mexicanos.

La primera de esas características consiste en el contrastante ritmo de incremento de commuters que se observa entre los periodos de 1963 a 1966 y de 1966 a 1975. En efecto, mientras que durante el primero de esos periodos el contingente de commuters aumentó en casi diez mil personas o en $27.7 \%$ en relación con 1963. Durante el lapso de 1966 a 1975 los commuters mexicanos sólo se incrementaron en alrededor de $18.5 \%$ (i.e. 8076 personas) en relación con 1966. 
CUADRO 1

Commuters mexicanos identificados en la frontera México-Estados Unidos de América (1963-1975)

\begin{tabular}{|c|c|c|c|c|c|}
\hline \multirow{2}{*}{$\begin{array}{l}\text { Puertos } \\
\text { fronterizos }\end{array}$} & \multicolumn{5}{|c|}{ Año } \\
\hline & 1963 & $1966^{*}$ & 1967 & 1969 & 1975 \\
\hline Total & 34209 & 43687 & 40176 & 47876 & 51763 \\
\hline \multicolumn{6}{|l|}{ EUA - México } \\
\hline Brownsville/Matamoros & 1796 & 2032 & 1917 & 2306 & 2311 \\
\hline Progreso/Nvo. Progreso & - & - & 50 & 82 & 53 \\
\hline Hidalgo/Reynosa & 366 & 1163 & 937 & 1063 & 970 \\
\hline Roma/Cd. M. Alemán & 89 & 208 & 73 & 105 & 785 \\
\hline Laredo/Nvo. Laredo & 2490 & 2581 & 2669 & 3312 & 2489 \\
\hline Eagle Pass/P. Negras & 1586 & 1604 & 1635 & 1968 & 2525 \\
\hline Del Río/Cd. Acuña & 237 & 513 & 317 & 132 & 401 \\
\hline Presidio/Ojinaga & - & - & 24 & 45 & 16 \\
\hline Fabens/El Porvenir & 307 & 274 & 279 & 326 & 352 \\
\hline Ft. Hancock/El Porvenir & - & - & 53 & 54 & 136 \\
\hline El Paso/Cd. Juárez & 13492 & 8592 & 11760 & 13140 & 14429 \\
\hline Columbus/Palomas & - & - & 30 & 31 & 35 \\
\hline Douglas/Agua Prieta & 307 & 418 & 380 & 496 & 323 \\
\hline Naco/Naco & 202 & 127 & 94 & 112 & 132 \\
\hline Nogales/Nogales & 1464 & 1614 & 1118 & 1371 & 993 \\
\hline Sasabe/Sasabe & - & - & 3 & 7 & 9 \\
\hline Lukeville/Sonoita & - & - & - & 1 & 6 \\
\hline San Luis/San Luis, R.C. & 1239 & 4234 & 3553 & 3616 & 4402 \\
\hline Andrade/Algodones & - & - & 3 & 14 & 128 \\
\hline Calexico/Mexicali & 4692 & 7616 & 7690 & 8788 & 6019 \\
\hline Tecate/Tecate & - & - & 56 & 66 & $\mathbf{5 0}$ \\
\hline San Ysidro/Tijuana & 5855 & 9281 & 7535 & 10841 & 15199 \\
\hline Otros Puertos & 87 & 3430 & - & - & - \\
\hline
\end{tabular}

(*) El conteo de este año incluyó tanto a commuters mexicanos, como a ciudadanos americanos residentes en México que trabajaban en su país; además, de los 43687 mexicanos se contabilizaron un total de 18259 ciudadanos estadunidenses.

Fuentes: 1963 a 1967: Report of the Select Commission on Western Hemisphere Immigration, Government Printing Office, 1968, Washington. 1969 y 1975; North, D. y Houston, M.: 1976; A-9.

La coincidencia del acelerado incremento de commuters entre 1963 y 1966 con el finiquito de la Ley Pública 78 de Estados Unidos -vigente de 1942 a 1964- también conocida como "Programa de braceros", permite plantear la posibilidad de que un 
número importante de quienes participaban del Programa de braceros se reincorporaran como commuters a las actividades productivas en Estados Unidos después de 1964, mediante la gestión de la forma de inmigración I-151.

Un segundo rasgo que se puede advertir a partir de la información del cuadro 1, es el relativo a la significativa participación como transmigrantes de los ciudadanos americanos que residen en las localidades mexicanas y que laboran en Estados Unidos. $\mathrm{Al}$ respecto, los datos correspondientes a 1966 -año en que también se contabilizaron los ciudadanos americanos que son parte del contingente de los transmigrantes- permiten observar que por cada siete commuters mexicanos había aproximadamente tres transmigrantes (i.e. $29.5 \%$ del total) que siendo ciudadanos americanos, a la vez residían en localidades fronterizas de México y trabajaban en Estados Unidos.

La tercera característica a mencionar en relación con los commuters mexicanos contabilizados por el SIN entre 1963 y 1975, consiste en su cambiante distribución geográfica. En este caso se puede observar que, en los puertos fronterizos localizados en el estado de Texas (i.e. de Brownsville a El Paso en el cuadro 1) en 1963 se ubicó a $59.5 \%$ de los commuters mexicanos, proporción que se redujo a $47.3 \%$ del total registrado para 1975 ; que en los puertos del estado de Arizona (i.e. de Douglas a San Luis en el cuadro 1), la participación se incrementó de $9.3 \%$ a $11.3 \%$ del total de commuters durante ese periodo, y por último, que en las localidades fronterizas de California (i.e Andrade, Calexico, Tecate y San Ysidro) el porcentaje de commuters mexicanos aumentó de $30.8 \%$ a $41.3 \%$ entre 1963 y 1975 .

Es decir, en otros términos, que a través de los conteos del SiN se aprecia una redistribución de los commuters mexicanos hacia los estados fronterizos del oeste. Este proceso de redistribución se presenta de manera acentuada en el caso del estado de California, pues entre 1963 y 1966 absorbió más de 64\% de los nuevos commuters contabilizados, y de 1966 a 1975 logró captar más de $55.0 \%$ del incremento total registrado durante ese periodo en la frontera entre Estados Unidos y México.

Después de los conteos realizados por el SIN, las cuantificaciones más actualizadas disponibles en relación con la magnitud del contingente de commuters en toda la frontera entre México y Estados Unidos son las estimadas a través de encuestas (de 1987 a 1991) en localidades mexicanas, las que ubican el número de transmigrantes (i.e. tarjetas verdes commuters, ciudadanos americanos e ilegales transmigrantes) en el rango de 80 a 100 mil personas (Alegría, 1990: 8; Arámburo y Fuentes, 1992: 68). 
Para el caso específico de Baja California, dos de las estimaciones más recientes sobre el número de transmigrantes que residen en la entidad se han generado a partir de las Encuestas Demográficas de Baja California de 1986 y 1990 (IIS-UABC/Conepo-BC, 1987 y 1993). Los resultados de ambas encuestas han sido previamente analizados con propósitos de evaluación numérica (Estrella, 1991; IIS-UABC/Conepo-BC, 1987) de su consistencia interna y externa, lográndose establecer que las estimaciones de población se ubican dentro de rangos consistentes con la trayectoria demográfica de la entidad, así como que la declaración de las estructuras por sexo y edad de la población y sus preferencias digitales definen una calidad "aceptable" de la información, a partir de clasificaciones convencionalmente aceptadas para los valores de índices como los de Myers y Whipple (Shryock et al., 1976).

En el caso de los grupos de transmigrantes que aquí nos interesan, la información calculada con el programa Clusters (Verma y Pearce, 1986) que se presenta en la primera parte del anexo 1, permite advertir que las estimaciones puntuales que se generan utilizando las encuestas de 1986 y 1990 para tarjetas verdes, ciudadanos norteamericanos y rodinos, se caracterizan por contar con errores estándar muy próximos o inferiores a 5000 personas, los cuales en términos de errores relativos indican niveles predominantemente por debajo del orden de .150. Los niveles correspondientes a los errores estándar de las estimaciones de proporciones por categoría migratoria y para la distribución por sexos al interior de las mismas, salvo en el caso de las mujeres rodino, también indican que los errores relativos fluctúan entre .150 y .100.

A partir de las estimaciones derivadas de esas dos encuestas resulta posible advertir -tal como lo muestran los cuadros 2 y 3que a raíz de la puesta en marcha de los programas TAE de la Ley Simpson-Rodino, el número de commuters mexicanos ${ }^{3}$ en Baja California se incrementó de 28000 en 1986 a casi 72000 en 1990. Es decir que, como consecuencia tanto del aumento de tarjetas verdes por otorgamiento de esa calidad migratoria basada en cuotas, como por el surgimiento del grupo rodino a través de los programas de TAE, el grupo de commuters se amplió en un número aproximado de 44 mil personas entre 1986 y 1990.

Además, en relación con ese aumento en el número de commuters, se debe señalar que del total de nuevos commuters, $66 \%$ se integra a partir del grupo de rodinos (i.e. 29 mil personas). Di-

${ }^{3}$ En estos datos se excluye a los ciudadanos de Estados Unidos que residen en Baja California. 


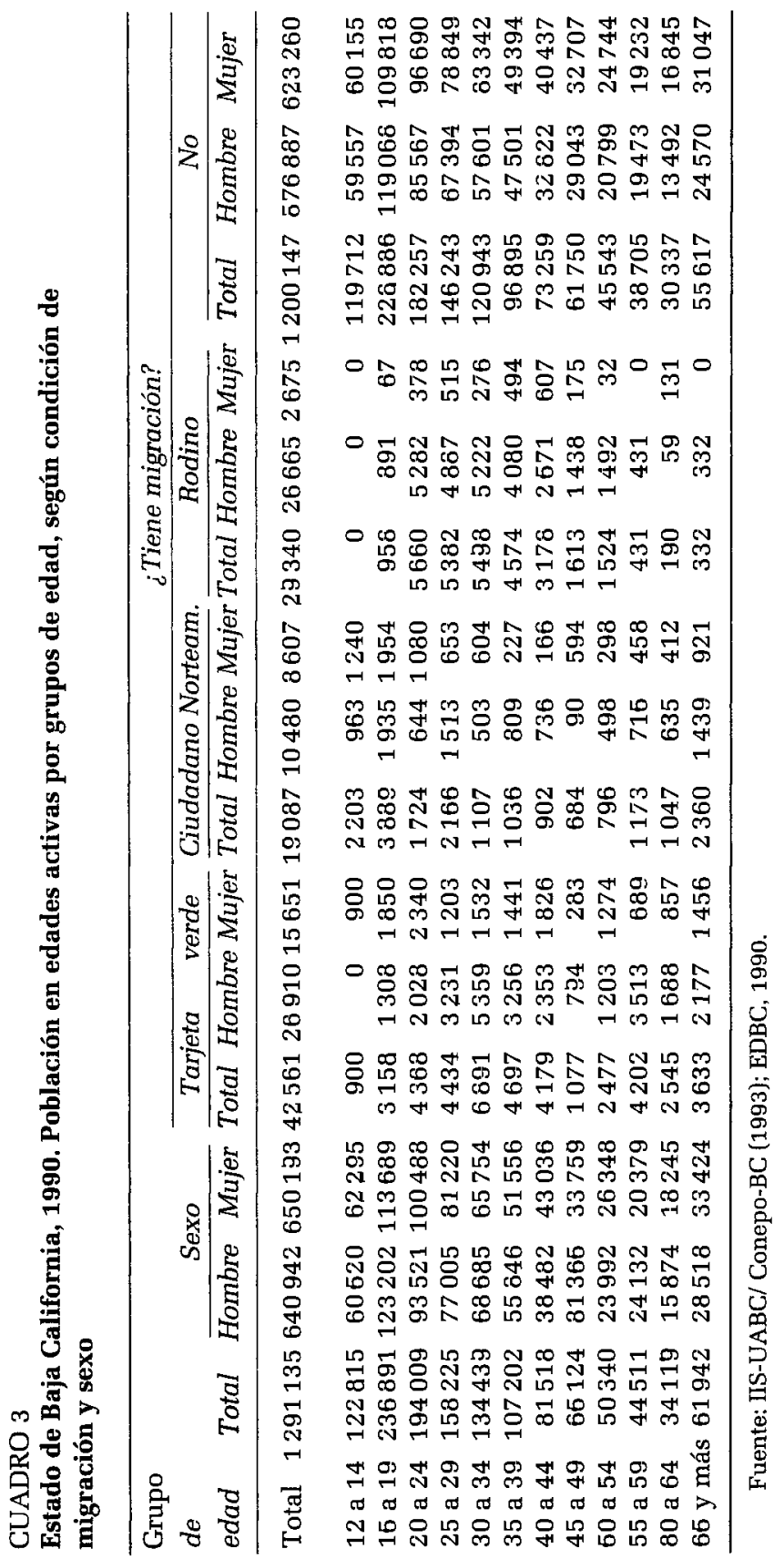


cho en otros términos, de cada tres nuevos miembros integrados al grupo de commuters entre 1986 y 1990, dos se incorporaron a través del programa de TAE que implicaba la "Enmienda Schumer" de la Ley de Reforma y Control de Inmigración del 6 de noviembre de 1986.

Una de las modificaciones más relevantes que se originan a partir de este incremento en el número de commuters, y que constituye el segundo elemento a destacar, es la referida a los cambios en la composición por sexo del grupo de commuters. En ese sentido, los datos de los dos cuadros anteriores permiten observar que los hombres representaban $66 \%$ del total de tarjetas verdes en 1986 , porcentaje que se incrementa hasta $74.5 \%$ para 1990 , al considerar tanto a tarjetas verdes como a rodinos.

Se debe notar, sin embargo, que esta alteración en la composición por sexo no radica en modificaciones en la estructura por sexos del grupo de tarjetas verdes dado que, de 1986 a 1990, en ese grupo los hombres disminuyeron su participación proporcional de 66 a $63 \%$ durante dicho periodo.

La explicación al cambio en la relación de hombres y mujeres en el grupo de commuter (i.e. de dos hombres por cada mujer en 1986 a tres hombres por cada mujer en 1990), se localiza en la composición por sexos que adoptó el nuevo contingente integrado por los rodinos. En efecto, como lo indican los datos del cuadro 3, en este grupo la relación por sexo es de nueve hombres por cada mujer, lo que pone en evidencia un claro proceso de selectividad por sexo en la integración del grupo rodino.

En términos absolutos, el efecto de la selectividad por sexo se expresa en el hecho de que de los 44 mil nuevos commuters que se detectaron entre 1986 y 1990, 35 mil son hombres (i.e. virtualmente $80 \%$ ), y de que de este total más de 26 mil hombres se incorporaron como rodinos al contingente de commuters. Es decir, se observa que por cada 10 personas que se incorporaron como nuevos commuters, entre 1986 y 1990 , seis son hombres y a la vez pertenecen al grupo de rodinos. A este proceso de selectividad por sexo que se evidencia en la integración del grupo de rodinos se debe agregar, como tercer elemento a señalar, la alta concentración en grupos de edad joven que caracteriza a las migraciones laborales, y que en este caso se acentúa para el subgrupo de los rodinos de Baja California, en el que la edad modal se ubica en el grupo de 20 a 24 años.

Las modificaciones demográficas en el grupo de commuters antes señaladas, se acompañaron de variaciones que permiten observar en el rubro de la estructura familiar del grupo de transmigrantes que residen en Baja California el acentuamiento en la 
participación de jefes de hogar en esta práctica migratoria laboral, a través de la incorporación de éstos como rodinos; un incremento sustantivo de la categoría de hijos del jefe del hogar por medio de la participación de los hijos varones del jefe del hogar en la migración laboral como rodinos, y una evidente selectividad por edades que redundó en que los hombres rodinos -tanto jefes como hijos del jefe del hogar- se caractericen por presentar las medias de edad más bajas (i.e. 36 y 24 años, respectivamente) de todos los grupos con documentación para laborar legalmente en Estados Unidos. 4

En el rubro de los antecedentes de migración interna se logra detectar que, en evidente contraste con los demás grupos, el de los rodinos se integra preponderantemente de hombres nativos de Baja California. Es decir, que mientras que en el total de la población y en otros grupos (e.g. ciudadanos americanos) el peso porcentual de los hombres nativos de la entidad no llega en ningún caso a $27 \%$, los hombres nativos de Baja California representan $42 \%$ del grupo de rodinos.

Otro elemento a mencionar en materia de los cambios observados en el grupo de commuters a raíz de la incorporación de los rodinos durante el periodo comprendido de 1986 a 1990 , es el referido a la escolaridad con que cuentan estos grupos de la población. En conjunto, desde diferentes perspectivas, se puede advertir que entre los rasgos más relevantes en este rubro de comparación, destacan el hecho de que la proporción de personas con nivel educativo de preparatoria o superior es de $26.7 \%$ para el grupo rodino, mientras que para el total de la población el porcentaje es sólo del orden de $19.1 \%$, que observado en términos de la media de los años de escolaridad, con la excepción de los residentes de Baja California que cuentan con nacionalidad norteamericana, el grupo de rodinos en su conjunto presenta las medias de escolaridad más altas tanto en el total como entre los hombres; que una vez controlados los efectos de las estructuras de edad, se observa que tanto para hombres como para mujeres del grupo rodino, las personas incluidas en el rango de 20 a 34 años de edad cuentan con medias de escolaridad superiores a las de la población sin documentos para laborar en Estados Unidos, y que tanto los jefes de hogar hombres como los hijos e hijas del jefe de hogar que son rodinos y que representan $88 \%$ del total del grupo cuentan con medias de escolaridad superiores a las de la población total del estado, y a las de la población que no posee el estatus migratorio que le permita laborar en Estados Únidos. po de commuters de Baja California, véase Estrella, 1992. 
El rubro final a considerar en materia de los cambios observados a nivel individual en los commuters, es el relativo a su participación en las actividades económicas. En términos de la población económicamente activa (PEA), se puede establecer que la incorporación de residentes de Baja California al grupo de commuters entre 1986 y 1990, implicó una modificación en la que se puede observar que mientras que en 1986 los tarjetas verdes representaban $3.2 \%$ del total de la PEA del estado, para 1990 el grupo commuter que integran los tarjetas verdes y los rodinos ya representa $8 \%$ de la PEA de la entidad. En este proceso, el surgimiento del grupo de rodinos adquirió un papel preponderante, puesto que para 1990 los más de 27 mil roldinos que participan en las actividades económicas ya representaban por sí solos $4.1 \%$ de la PEA de Baja California.

En materia de la participación del grupo de commuters en las actividades económicas destacan, por último, los rasgos característicos de una alta concentración de quienes cuentan con estatus migratorio que les permite laborar en Estados Unidos en las actividades de la rama agropecuaria, y una acelerada diversificación de la participación de los integrantes del grupo rodino hacia ramas diferentes a las de la agropecuaria, con especial énfasis de incorporación a la rama de la construcción.

\section{Frontera y estrategias de sobrevivencia}

La propuesta conceptual de abordar el análisis de la movilidad de la población utilizando como unidad de análisis al grupo doméstico, adopta como supuesto básico el de que

cuando la suma de ingresos monetarios y no-monetarios son suficientes para alcanzar o incrementar la calidad y cantidad deseada de consumo e inversión, es poco probable que se presente la migración temporal o permanente ... mientras que... cuando el hogar no es capaz de mantener el nivel deseado de ingreso a pesar de las estrategias que ha adoptado, o cuando en otro lugar existen alternativas viables para mejorar su condición (descontando los costos de la migración), es probable que el resultado sea la migración definitiva (Wood, 1982: 314, traducción mía).

La evidencia empírica acumulada desde la postulación inicial de estas premisas, ha permitido generar un proceso de refinamiento gradual de estas últimas en al menos dos áreas generales.

$\mathrm{Al}$ respecto, la primera área en la que se han logrado especificaciones sustantivas, es la correspondiente a la diferenciación 
entre factores que promueven la migración de uno o varios de los miembros de un grupo doméstico, de aquellos factores más estrechamente relacionados con la posibilidad de que sea el grupo doméstico en su conjunto el que se movilice. En esta línea de análisis, por ejemplo, Root y De Jong (1991) han proporcionado evidencia referida al caso de la provincia de llocos Norte, en Filipinas, la cual permite observar que los factores explicativos de la migración de sólo uno o varios de los miembros del grupo doméstico difieren de las variables asociadas con los casos de la migración de hogares completos (Root y De Jong, 1991: 128-223).

Más allá del carácter puntual de estos resultados, lo que interesa rescatar es la consideración de que aun cuando en ciertos casos la migración de todo el grupo doméstico se constituye como "la estrategia" de aquél, la movilidad de uno o varios de sus miembros no es una opción excluyente (véase Lauby y Stark, 1988). Es decir, que la movilidad de parte de los integrantes de un grupo doméstico puede ser un elemento del conjunto más amplio de acciones que integran la estrategia de reproducción material de esa unidad doméstica.

La segunda área en la que la experiencia de la investigación ha proporcionado elementos para adecuar las premisas del marco conceptual que recurre al grupo doméstico como unidad de análisis de la movilidad de la población, es la concerniente al papel que desempeñan lo que se han denominado "factores contextuales comunitarios" en las decisiones de migración (Bilsborrow et al., 1987; Findley, 1987). En un sentido amplio, el análisis de este tipo de factores ha tenido como intención recuperar el estudio de los procesos macro-estructurales que influyen en la movilidad. Sin embargo, ubicados en esta propuesta conceptual, el análisis de estos factores busca generar respuestas a la pregunta de por qué, por ejemplo, unidades domésticas aparentemente similares -social y demográficamente- pero ubicadas en regiones, áreas o localidades diferentes, no asumen estrategias de reproducción análoga en relación con la migración.

Con el fin de incorporar las especificaciones conceptuales antes mencionadas, a continuación nos proponemos establecer desde tres niveles de análisis (i.e. individual, del grupo familiar y del contexto territorial) qué factores se asocian con los grupos domésticos de Baja California que incluyeron en su estrategia de reproducción a la migración internacional a partir de 1986. En este sentido, la descripción antes hecha de las características de los individuos que forman parte del grupo de rodinos, requiere ser complementada por los rasgos que definen el perfil tanto de los hogares que utilizan la migración internacional, como de su distribución en el ámbito de los cuatro municipios de la entidad. 
En relación con el nivel de análisis correspondiente a los grupos domésticos, cabe destacar que el perfil de los hogares que incorporaron después de 1986 a uno o más de sus miembros al contingente de commuters, se define a partir de una concentración de los grupos domésticos que cuentan con rodinos en los tipos de hogar nucleares completos y extendidos por parentesco, particularmente los jefaturados por hombres; por una participación acentuada de los hogares con commuters en los rangos que identifican números de integrantes relativamente grandes; por una representación más que proporcional de los grupos domésticos con rodinos entre aquellos hogares que se encuentran en etapas tempranas del ciclo vital, hogares en los que sin embargo se observan medias de escolaridad altas, bajas proporciones de personas en edades activas, cargas económicas definidas por bajas proporciones de estudiantes, bajos índices de dependencia adulta y total, pero altos índices de dependencia infantil, y una escasa experiencia migratoria interna e internacional de los grupos domésticos con rodinos.

A la vez, en relación con las características del contexto en el que se ubican los grupos domésticos que se incorporaron al contingente de commuters, se debe destacar que los condicionantes contextuales generaron tres efectos generales en términos de la distribución urbano-rural y municipal de los hogares con migrantes a saber:

i) Un incremento de la participación del municipio de Mexicali en el total de commuters de la entidad, a raíz de la cual en este municipio se localizan ahora más de $63 \%$ de los hogares que cuentan con rodinos.

ii) El surgimiento de un patrón divergente de selectividad por sexo del jefe del hogar en los municipios de Mexicali y Tijuana (que en conjunto aglutinan a más de $\mathbf{9 6 \%}$ del total de los grupos domésticos con rodinos de la entidad), pues mientras que en el primero sólo $6 \%$ de los hogares con rodinos están jefaturados por mujeres, en el segundo el porcentaje correspondiente alcanza el nivel de 18 por ciento.

iii) Finalmente, también aparece un efecto de selectividad urbano-rural de sentido inverso en los municipios de Mexicali y Tijuana, puesto que mientras que en el primero los grupos domésticos que cuentan con rodinos y que residen en áreas rurales representan $32 \%$ de su total, en el segundo se presenta una concentración más que proporcional de hogares con rodinos en el área urbana. 
Con base en estos antecedentes y con el fin de evaluar de manera conjunta los factores que, desde diversos niveles de agregación afectaron las decisiones de los grupos domésticos para incorporar uno o más de sus miembros al contingente de commuters de Baja California, a continuación se analizan los efectos que generaron cuatro de los factores que evaluaciones preliminares identificaron como significativos.

Para el logro de ese propósito se recurre exclusivamente a la comparación analítica entre grupos domésticos sin migrantes y grupos domésticos con rodinos (i.e. se excluyen los grupos domésticos con tarjetas verdes $\mathrm{y}(\mathrm{o})$ ciudadanos americanos), a fin de identificar con precisión los elementos de diferenciación entre hogares que recurrieron recientemente a la migración internacional legal como parte de su estrategia de reproducción, y hogares que no han recurrido a esta opción.

Además, dado que hemos propuesto como unidad de análisis de las decisiones y procesos de migración al grupo doméstico, y dada la delimitación establecida antes, se decidió utilizar la dicotomía categórica grupo doméstico sin migrante y grupo doméstico con rodino, como la variable dependiente en el modelo estadístico aplicado.

Por tal motivo, tomando en consideración la naturaleza categórica de nuestra variable dependiente y de la mayoría de las variables independientes utilizadas (vid infra), hemos recurrido a los modelos de regresión Logito que, por ser un caso específico del modelo general de regresión logarítmica-lineal, se considera análogo al modelo ordinario de regresión lineal para variables dependientes continuas (Aldrich y Nelson, 1984). La versión general de los modelos de regresión logarítmica-lineal, busca reproducir las frecuencias observadas en las celdas que forman las categorías de variables incluidas en una tabulación cruzada, por medio de su transformación a logaritmos. Con los valores logarítmicos se genera el cómputo de coeficientes (i.e. Lambda), que se derivan de restar a los promedios de los logaritmos de cada categoría, y al promedio general (i.e. los marginales) los valores de los logaritmos de cada combinación de categorías, con lo que se obtiene una cuantificación del incremento, decremento o ausencia de efectos (i.e. al adquirir Lambda valores positivos, negativos o muy próximos a cero, respectivamente) que ejerce una combinación dada de categorías sobre los valores promedio.

Este mismo principio se encuentra en el caso específico de los modelos Logito, aun cuando en ellos se parte ya no sólo del logaritmo de la frecuencia en una celda, sino del logaritmo de la razón de frecuencias entre categorías de la variable considerada como 
dependiente. En su formulación general el modelo Logito puede ser expresado como: donde:

$$
\operatorname{Ln}(F 0 j k / F 1 j k)=2(I x+l x y+I x n \ldots+l x y n)
$$

$x=$ la variable dependiente,

$y, n=$ las variables independientes,

$0,1=$ valores de las categorías de la variable dependiente,

$j, k=$ valores de categorías de las variables independientes,

$F 1 j k$ = frecuencias de las celdas tabulares,

lx...lxyn = coeficientes Lambda.

En estos modelos, por tanto, se analiza el logaritmo natural $(L n)$ de la razón de frecuencias esperadas entre categorías de la variable dependiente $(F 0 j k / F 1 j k$ ), y su interpretación es la de la probabilidad condicional (i.e. Conditional Odds o PC) de que un individuo seleccionado al azar sea observado dentro de la categoría de interés en lugar de en la otra categoría (Knoke y Burke, 1980: 9), probabilidad que se obtiene a través de la siguiente transformación:

$$
\mathrm{PC}=1 /[\operatorname{Exp}\{2(l x+l x n+l x n \ldots+1 x y n)\}] .
$$

A través de esta última ecuación se logra obtener una estimación sumaria de los efectos que generan las diversas categorías de las variables independientes sobre la variable dependiente de manera directa y a través de sus interacciones (i.e. por los valores de los coeficientes $L a m b d a$ ), la cual adquiere el valor de 1 cuando no existe diferencia entre las categorías de la variable dependiente, mayor que uno cuando la categoría de referencia (codificada $=0$ ) para la variable dependiente aglutina casos más que proporcionalmente, y valores inferiores a uno cuando la categoría de la variable dependiente que se evalúa (codificada diferente de 0) incluye más casos que la categoría de referencia.

En este caso, pues, se integró un modelo Logito en el que la variable dependiente fue definida como la dicotomía grupos domésticos sin migrantes (núm. de casos $=13404$ ) y grupos domésticos con rodinos (núm. de casos $=1166$ ) $^{5}$ las que se codificaron como (Migint: $0=\sin$ migrantes; $1=$ con rodinos), en tanto que las categorías de las variables independientes incluidas en el modelo (n.b. en el segundo panel del anexo 1, se presentan las distribuciones muestrales y expandidas de estas variables), se definie-

${ }_{5}^{5}$ Ambos tamaños de muestra (i.e. núm.) corresponden a registros de individuos de 12 años y más de edad, en la "Encuesta Demográfica de Baja California", 1990 (Véase IIS-UABC/Conepo-BC, 1993). 
ron como sigue: relación de parentesco con el jefe del hogar (Relpargp: Jefe de Hogar $=0$, cónyuge del $\mathrm{JH}=1$, hijo (a) del $\mathrm{JH}=2$, otra relación de parentesco $=3$ ); sexo del jefe del hogar (Sexojh: hombre $=0$, mujer $=1$ ); número de integrantes del grupo doméstico (Numint: $0=$ hasta 4, 1 = más de 4), y municipios de residencia (Mpores: 0 = Mexicali, 1 = Tijuana, 2 = Ensenada y Tecate).

Al contar con este modelo en el que se evalúan efectos de las variables independientes Relpargp, Sexojh, Numint, y Mpores sobre la variable dependiente Migint, se procedió a estimar tanto el modelo "base" -en el que se supone ausencia de efectos directos entre las variables- como el que minimizara la magnitud de Chicuadrada de la razón de probabilidad (i.e. $L R \times 2$ ) y a la vez maximizara su nivel de significancia estadística al incluir efectos directos e interacciones entre las variables independientes. Los resultados de dicho procedimiento, así como los coeficientes Lambda e indicadores de significancia del modelo "seleccionado" se presentan en el cuadro 4.

La información presentada en el primer panel del cuadro 4 permite advertir que, en relación con el modelo "base" o de "independencia", el modelo "seleccionado" logra explicar más de $95 \%$ de la variación observada en la distribución de los grupos domésticos entre aquellos sin migrantes y los que cuentan con rodinos, a la vez que su significancia estadística es superior a $p=.600$.

Por su parte, los coeficientes Lambda del modelo "seleccionado" permiten observar -segundo panel del cuadro 4- que los efectos directos de mayor magnitud sobre las probabilidades condicionales para que un grupo doméstico cuente con rodinos se originan en la variable contextual del municipio de residencia (i.e. Migint ${ }^{*}$ Mpores); que a este efecto contextual le siguen en orden decreciente, los originados en el grupo doméstico mediante las características del número de integrantes y del sexo del jefe del hogar (i.e. Migint ${ }^{\star}$ Numint y Migint y Sexojh, respectivamente), y finalmente, que por su magnitud los efectos directos de menor importancia son los derivados de la característica individual de relación de parentesco con el jefe del hogar (i.e. Migint*Relpargp).

La combinación de esos efectos directos con las tres interacciones entre variables independientes que se incluyeron en el modelo "seleccionado", permite estimar las probabilidades condicionales $(P C)$ para que un grupo doméstico cuente con rodinos en función de la relación de parentesco con el JH, del sexo del JH, del número de integrantes del grupo doméstico, y del municipio de residencia. Dichas probabilidades condicionales, expresadas en términos de hogares sin migrantes por cada hogar con rodinos, se presentan en el cuadro 5 y se reproducen en la gráfica 1. 
CUADRO 4

Modelo logito de efectos, de características de individuos, de los hogares, y contextuales, en la adopción de migración en grupos domésticos

\begin{tabular}{|c|c|c|c|}
\hline \multirow[t]{2}{*}{ Modelos } & \multicolumn{3}{|c|}{ Estadisticas de bondad de ajuste } \\
\hline & $L R x 2 \ldots$ & $G L$ & $P \ldots$ \\
\hline Modelo de "Independencia" & 702.38921 & 47 & 0.000 \\
\hline Modelo "Seleccionado" & 32.14850 & 35 & 0.606 \\
\hline \multicolumn{4}{|c|}{ Efectos directos e interacciones en modelo "Seleccionado" } \\
\hline Parámetro & Coef. Lambda & Err. Std. & Valor Z \\
\hline Migint & 1.4398536476 & .03758 & $38.31448^{*}$ \\
\hline Migint y Relpargt & $\begin{array}{r}.0567045765 \\
.0341058218 \\
-.0065460000\end{array}$ & $\begin{array}{l}.02828 \\
.02980 \\
.02547\end{array}$ & $\begin{array}{l}2.00546 \text { * } \\
1.14445 \\
-.25704\end{array}$ \\
\hline Migint y sexo JH & -.2000878956 & .03677 & $-5.44148^{\star}$ \\
\hline Migint y Numint & .3067741091 & .03717 & $8.25238^{*}$ \\
\hline Migint y Mpores & $\begin{array}{r}-.4263554236 \\
.1573462059\end{array}$ & $\begin{array}{l}.02469 \\
.02872\end{array}$ & $\begin{array}{r}-17.26709^{\star} \\
5.47956^{\star}\end{array}$ \\
\hline $\begin{array}{l}\text { Migint y sexo JH y } \\
\text { Numint }\end{array}$ & -.2115913170 & .03672 & $-5.76194^{*}$ \\
\hline Migint y Numint y & & & \\
\hline Mpores & $\begin{array}{r}-.0244639491 \\
.0725138144\end{array}$ & $\begin{array}{l}.03791 \\
.04077\end{array}$ & $\begin{array}{l}-.64531 \\
1.77882\end{array}$ \\
\hline Migint y sexo JH y & & & \\
\hline Numint y Mpores & $\begin{array}{r}.1341105378 \\
-.0875715168\end{array}$ & $\begin{array}{l}.03502 \\
.03676\end{array}$ & $\begin{array}{l}3.82972^{*} \\
-2.38193^{*}\end{array}$ \\
\hline
\end{tabular}

* Estadísticamente significativos al nivel de ( $p=<0.05)$.

Nota: Para la definición de variables ver texto supra. Los coeficientes $L a m b$ $d a$ corresponden sólo hasta la penúltima categoría de la última o penúltima variable(s) independiente(s). 


\section{CUADRO 5}

Baja California, 1990. Probabilidades condicionales para que un G.D. tenga rodinos. Efectos individuales, de hogares y contextuales (hogares sin migrantes por cada hogar con rodinos*)

\begin{tabular}{lrrrrrr}
\hline Relación de & \multicolumn{5}{c}{ Número de integrantes y municipio de residencia } \\
\cline { 2 - 7 } $\begin{array}{l}\text { parentesco y } \\
\text { sexo del JH }\end{array}$ & Ens. y Tec. Mexicali & Tijj. & Ens. y Tec. Mexicali & Tij. \\
\hline Jefe del hogar & & & & & & \\
$\quad$ JH Hombre & 22.9 & 8.6 & 21.5 & 22.9 & 3.8 & 15.6 \\
$\quad$ JH Mujer & 143.3 & 26.1 & 158.4 & 18.1 & 6.2 & 10.5 \\
$\begin{array}{l}\text { Cónyuge del jefe } \\
\quad \text { JH Hombre }\end{array}$ & 21.9 & 8.2 & 20.5 & 21.9 & 3.6 & 14.9 \\
$\quad \begin{array}{l}\text { JH Mujer } \\
\text { Hijo/hija del J H }\end{array}$ & 137.0 & 24.9 & 151.4 & 17.3 & 5.9 & 10.0 \\
$\quad$ & & & & & & \\
$\quad$ JH Hombre & 20.2 & 7.6 & 18.9 & 20.2 & 3.3 & 13.7 \\
$\quad$ JH Mujer & 126.3 & 23.0 & 139.5 & 16.0 & 5.4 & 9.2 \\
$\begin{array}{l}\text { Otro parentesco } \\
\quad \text { JH Hombre }\end{array}$ & 17.3 & 6.5 & 16.2 & 17.3 & 2.9 & 11.8 \\
$\quad$ JH Mujer & 108.1 & 19.7 & 119.5 & 13.7 & 4.7 & 7.9 \\
\hline
\end{tabular}

* Se calcularon a partir de datos del cuadro 4, y para estimarlas en términos de hogares sin migrantes por cada hogar con rodinos, se utilizó la fórmula:

$\mathrm{PC}=1 /\left[\operatorname{Exp}\left\{2^{*}(l x+l x y+l x n \ldots+l x y n)\right\}\right]$.

GRÁFICA 1 Baja California. Probabilidades condicionales para que un hogar cuente con Rodinos

(factores individuales, familiares y contextuales)

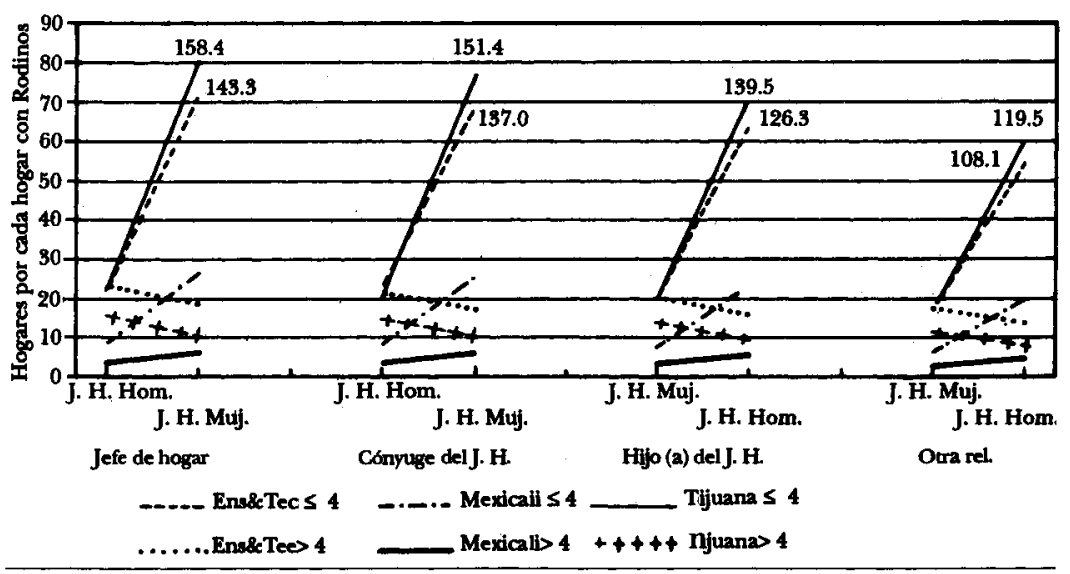

Fuente: Cuadro 5

Nota: Los valores de Ensenada, Tecate y Tijuana que aparecen en la gráfica se escalaron a $1 / 2$. 
A partir de los datos contenidos en el cuadro 5, se puede apreciar la conformación de al menos cinco patrones generalizados en las PC para que un hogar cuente con rodinos. El primero de éstos consiste en el hecho de que el número de hogares sin migrantes por cada hogar con rodinos, siempre es menor en el municipio de Mexicali que en los restantes municipios para todas las categorías comparables de relación de parentesco, número de integrantes del grupo doméstico y sexo del jefe del hogar. Este patrón, que se define por la ubicación más próxima a la base de la gráfica 1 de las dos rectas de Mexicali, que las correspondientes a las otras dos categorías municipales, indica que en el municipio de Mexicali las PC para que un hogar cuente con rodinos son las más altas.

El segundo patrón generalizado que se puede observar en los datos del cuadro 5 es el relativo a que -dentro de cada una de las tres categorías municipales- los grupos domésticos que cuentan con más de cuatro integrantes presentan los números más bajos de hogares sin migrantes por cada hogar con rodinos. La excepción a esta configuración la constituyen los grupos domésticos de Ensenada y Tecate con jefes de hogar hombres, en los que no se presentan diferencias por el número de integrantes del grupo doméstico, lo cual se aprecia gráficamente como la unión de las líneas de estos municipios en los puntos correspondientes a las categorías de jefe de hogar hombre.

En la misma gráfica 1 se puede observar el tercer rasgo de carácter general que presentan las $\mathrm{PC}$ para que un grupo doméstico cuente con rodinos, el cual consiste en que -para todos los municipios y todas las categorías de relación de parentesco- en los hogares de hasta cuatro integrantes, los que son jefaturados por hombres siempre presentan un número menor de hogares sin migrantes por cada hogar con rodinos, que el correspondiente a los grupos domésticos jefaturados por mujeres.

Dada la ordenación de las categorías por sexo del jefe del hogar, este rasgo se manifiesta gráficamente en la pendiente positiva que adquieren todas las rectas correspondientes a grupos domésticos integrados hasta por cuatro miembros, las cuales indican que mientras que en el caso de estos grupos jefaturados por mujeres de los municipios de Tijuana, Ensenada y Tecate, por cada hogar con rodinos existen entre 108 y 158 hogares sin migrantes; en el caso del municipio de Mexicali sólo existen entre 20 y 25 hogares sin migrantes por cada hogar con rodinos.

El cuarto patrón que se identifica en los datos del cuadro 5, es el relativo al efecto inverso de las categorías de sexo del jefe del hogar en las probabilidades condicionales para que un hogar 
cuente con rodinos en los grupos domésticos con más de cuatro integrantes. Aquí se puede advertir que, mientras que en el municipio de Mexicali se conserva el patrón en el que los grupos domésticos jefaturados por hombres presentan menos hogares sin migrantes por cada hogar con rodinos, en los municipios de Tijuana, y de Ensenada y Tecate ese patrón se revierte.

En ese sentido, la gráfica 1 permite observar que las rectas correspondientes a los grupos domésticos de más de cuatro integrantes de Tijuana, Ensenada y Tecate son las únicas que presentan pendientes negativas, indicando que en esos municipios el número de hogares sin migrantes por cada hogar con rodinos es inferior para los jefaturados por mujeres (i.e. en el rango de 18.1:1 a 7.9:1, dependiendo de las categorías de relación de parentesco) que para los encabezados por hombres, los cuales se ubican dentro del rango de entre 22.9:1 y 11.8:1 hogares sin migrantes por cada hogar con rodinos, en función de las categorías de relación de parentesco.

El último rasgo generalizado a destacar a partir de los resultados de este modelo que incorpora la interacción de las características de los individuos, los hogares y el contexto en que éstos se ubican sobre las PC para que un grupo doméstico cuente con rodinos, es el concerniente al efecto que generan las categorías de relación de parentesco sobre dichas probabilidades. Al respecto, tanto la información del cuadro 5 como de la gráfica 1, permiten observar que el efecto directo de esta variable genera un patrón de descenso creciente del número de hogares sin migrantes por cada hogar con rodinos, desde el punto de álgido que define la categoría de jefe de hogar (a la que siguen en orden decreciente la de cónyuge y la de hijo(a) del jefe del hogar, respectivamente), hasta el nivel más reducido que se asocia con la categoría de otra relación de parentesco con el jefe del hogar.

\section{Implicaciones y recomendaciones}

El conjunto de rasgos identificados a nivel individual y a nivel de los grupos domésticos que incluyen entre sus miembros a rodinos, nos ha permitido establecer que las características asociadas a los grupos con nuevos migrantes efectivamente aportan elementos que apoyan la hipótesis general de que, durante la coyuntura generada en 1986 por la combinación de las modificaciones de la legislación migratoria de Estados Unidos con la política de austeridad implantada por el gobierno mexicano, se amplió el espectro social de los grupos domésticos de Baja California que incluyen a la migración laboral internacional legal como parte de su estrategia de reproducción. 
En relación con la política de austeridad gubernamental, se debe advertir que en la zona fronteriza del norte del país, la "década perdida" no sólo representó un estancamiento y(o) decrecimiento en sus niveles absolutos de desarrollo económico como en el resto de México, sino que además significó un retroceso en sus niveles relativos de desarrollo en comparación con los de otras áreas del país.

La descripción breve de tres de los principales elementos del comportamiento económico durante ese periodo (i.e los salarios, la inflación y la inversión pública), nos permiten ilustrar para Baja California la magnitud de ese retroceso en términos relativos. En primer lugar se debe mencionar que, entre enero de 1983 y diciembre de 1991, el salario mínimo general diario de las tres áreas geográficas en que actualmente se ha dividido el país (i.e. A, B y C), para esos fines se incrementó en $2829.7 \%$ para el área que incluye a Baja California (i.e. A); en $2868.7 \%$ para el área B y en $2945.2 \%$ para el área $C$.

En contrapartida, los índices nacional y estatal de precios al consumidor (IPC) se incrementaron, respectivamente, de un nivel de 149.3 y 150.5 en 1980 , al orden de 1599.7 y 1819.2 , para 1985. Al finalizar la década de los ochenta el IPC a nivel nacional fue de 17750.6 durante 1989, mientras que el correspondiente a Baja California alcanzó en el año de 1989 el nivel de los 20459.2 puntos (García, 1992: 38).

Paralelamente, tanto el gasto público estatal como la inversión pública federal (IPF) decrecieron en concordancia con el modelo de "austeridad" que progresivamente se impulsó a partir de la crisis de la deuda externa desatada en 1982. Así, por ejemplo, partiendo de un índice 100 en 1980, la IPF a nivel nacional se redujo a 58.2 en 1985 y a 27.9 durante 1989, en tanto que la IPF en Baja California se reducía, de un índice del 100 en 1980, a 35 en 1985 y a 16.1 en 1989 (García, 1992: 63-64).

Las políticas de contención del salario, de recortes a la inversión pública y la redistribución del ingreso que generó el proceso inflacionario se conjugaron, además, con los efectos "instantáneos" que generan en la frontera norte de México las sucesivas devaluaciones del peso frente al dólar desde 1976 hasta la fecha, para estructurar un contexto coyuntural que resultó extremadamente propicio para que -a partir de 1986- un espectro social ampliado de la población de Baja California aprovechara el recurso de la migración internacional legal que generó la aprobación de las enmiendas a la legislación de inmigración de Estados Unidos mediante la Ley Simpson-Rodino.

Entre los principales elementos que sustentan a esa hipótesis, destacan -por su relevancia a nivel individual, de los grupos 
domésticos y de los efectos contextuales- los referidos al carácter preeminente que adoptaron la relativamente reducida experiencia migratoria de quienes ahora forman parte del grupo de los rodinos, así como el marcado diferencial que favorece a este nuevo grupo de migrantes en materia de niveles de escolaridad.

Respecto al primero de esos elementos resulta pertinente recalcar, por una parte, que una característica recurrente consistió en la participación más que proporcional de nativos de Baja California en la conformación del grupo de rodinos, lo que puso en evidencia una relativa inexperiencia -individual y del grupo doméstico- en materia de migración interna. A la vez, por otra parte, se pudo observar que en términos de grupos domésticos, los que cuentan con rodinos son en los que existe una menor proporción de integrantes con experiencia en materia de migración laboral internacional.

Aunada a esa limitada experiencia previa en relación con la migración interna y a la migración laboral internacional, se observó que tanto a nivel individual de los rodinos como de los grupos domésticos de los que forman parte, estos grupos se caracterizaron por presentar niveles y medias de años de escolaridad que resultaron superiores a las correspondientes a los individuos sin estatus migratorio que les permita laborar en Estados Unidos, y a los grupos domésticos sin migrantes.

Esa combinación de ausencia de antecedentes de migración interna e internacional con el elevado nivel educativo asociado con los rodinos, en nuestra opinión identifica el perfil de un estrato socioeconómico de grupos domésticos diferente al predominante entre los commuters de Baja California hasta 1986, estrato que al incorporarse a través de los rodinos a los commuters, amplió el espectro social de los grupos domésticos de la entidad que incluyen a la migración laboral internacional legal como parte de sus estrategias de reproducción.

Partiendo del supuesto de la inclusión de grupos domésticos de estratos sociales que antes no recurrían a esa modalidad migratoria, y de que ello generaría la recomposición cuantitativa y cualitativa del grupo de los trabajadores commuters de Baja California, asumimos que era de esperarse que los efectos de selectividad por edad, sexo y relación de parentesco, estuvieran determinados por los objetivos de las estrategias de reproducción orientadas a la movilidad social ascendente de los grupos domésticos de ingreso reciente al conjunto de commuters.

En relación con ese planteamiento, los estudios realizados en África, Asia y Latinoamérica (Stark, 1982; Thadani, 1985; Trager, 1984) han discernido patrones diferenciales de movilidad por edad, 
sexo y relación de parentesco a partir de que la estrategia que los involucra tenga como objetivo la movilidad social ascendente o la sobrevivencia física del grupo doméstico. Cuando el objetivo de la estrategia es la movilidad ascendente, la evidencia es que en pocas ocasiones los migrantes son los padres de familia y que, en este caso, ellos financian la migración de sus hijos, además de que existen preferencias por sexo del migrante ya que, en ciertas culturas, se asume una mayor disposición de las mujeres para cumplir con la obligación de apoyar económicamente al grupo doméstico.

A ese conjunto de factores determinantes de la selectividad que genera el objetivo de la estrategia de reproducción, también se han agregado aquellos que surgen de la posición socioeconómica del grupo. En este sentido, por una parte, la investigación ha generado evidencia en relación con que los grupos de ingresos bajos tienen mayores posibilidades de recurrir a la migración, corroborando la perspectiva de las estrategias orientadas a la sobrevivencia física del grupo (Lipton, 1982). Sin embargo, por otra parte, también se han presentado resultados que indican tanto una relación positiva entre clase social y migración (Nelson, 1976) -respaldando parcialmente la perspectiva de las estrategias con fines de movilidad ascendente- como relaciones que varían en función del área que se estudia (Findley, 1987; Roberts, 1982).

En nuestro caso, los resultados permitieron observar la presencia de claras evidencias de selectividad en la constitución del grupo de rodinos, en al menos cuatro rubros genéricos. El primero de ellos corresponde al marcado grado de masculinización que se advierte en la composición de los rodinos, dado que más de $90 \%$ de este grupo está integrado por hombres. Al respecto cabe suponer que la orientación eminentemente agrícola que caracterizó a los programas de "Trabajadores Agrícolas Especiales" de la Ley Simpson-Rodino, influenció en forma determinante este proceso de selectividad por sexo.

Aunada a esa selectividad por sexo, una segunda característica consistió en la alta participación de dos categorías de relación de parentesco entre los miembros del grupo de nuevos commuters, jefes de hogar e hijos del jefe de hogar. Estas dos categorías, considerando exclusivamente a los jefes de hogar hombres y a los hijos varones, lograron representar más de $86 \%$ del total de los más de 29 mil rodinos de Baja California (i.e. 63.5\% son jefes de hogar hombres, y $22.5 \%$ son hijos varones del jefe del hogar).

Otro rubro con una marcada selectividad en la conformación del grupo rodino, es el relativo a la edad de quienes se incorporaron a esta nueva nueva práctica migratoria. A nivel general, se 
estableció que la edad modal del grupo de rodinos se ubica en el grupo de 20 a 24 años, y que $82.8 \%$ de ellos tiene entre 20 y 44 años de edad. En un nivel específico, además, se advirtió que los jefes de hogar hombres de este grupo de migrantes presentan las medias de edad más bajas de todas las categorías migratorias.

El cuarto rubro en el que se identifican elementos de selectividad en el grupo de rodinos en relación con la población que no cuenta con el status que le permita laborar legalmente en Estados Unidos, es el relativo a su nivel educativo. Al respecto conviene recordar, por una parte, que mientras sólo $18.3 \%$ de la población que no puede laborar legalmente en Estados Unidos tiene un nivel de escolaridad igual o superior al de preparatoria, entre el grupo de rodinos, $26.7 \%$ cuenta con estudios de preparatoria, profesional o superiores.

Las modalidades que asumieron esos elementos de selectividad por sexo, relación de parentesco, edad y escolaridad (como lo indican al menos parcialmente los resultados del modelo definido) de quienes forman parte del grupo de rodinos, nos permiten sugerir que en este caso la evidencia parece indicar que efectivamente se dio un proceso de selectividad determinado por una estrategia de movilidad ascendente de los grupos domésticos. En ese sentido, los dos elementos controvertibles de nuestra sugerencia -a partir de los resultados de estudios previos- estarían constituidos, por una parte, por la alta participación de jefes de hogar y, por otra, por la selectividad de hijos varones del jefe del hogar.

$\mathrm{Al}$ respecto se debe considerar que la alta participación masculina estuvo determinada, en este caso específico, por el carácter agrícola del programa de los TAE. De igual forma, es necesario recordar que en los grupos domésticos con rodinos jefaturados por hombres se observaron tanto altos índices de dependencia infantil, como bajas proporciones de miembros en edades activas, lo que en principio limitaba la selectividad por relación de parentesco, y que cuando los que se incorporaron fueron hijos del jefe del hogar lo hicieron quienes contaban con niveles educativos característicos de estratos socioeconómicos relativamente favorecidos, en los que es de esperar que sus estrategias de reproducción se orienten al sostenimiento del estatus o a la movilidad ascendente.

Más aún, otro elemento de apoyo a esta hipótesis lo constituye la amplia diversificación laboral que se detectó entre los rodinos quienes, a diferencia de otros subgrupos de commuters, no han permanecido limitados a las actividades agrícolas y han incursionado en actividades como la construcción, los servicios públicos gubernamentales y los relacionados con el turismo, dando muestras de movilidad laboral ascendente. Esa movilidad la- 
horal, por otra parte, en principio puede suponerse asociada con los mayores niveles de escolaridad observados entre los rodinos y se convierte en un rasgo complementario para entender el objetivo de lograr su movilidad social ascendente.

Un último elemento a considerar en relación con esta hipótesis, lo constituye el relativo a las posibles vías de evaluación respecto al "éxito" o "fracaso" de las estrategias orientadas a la movilidad social ascendente. En el caso que nos ocupa, sin lugar a dudas, el procedimiento ideal para dicha evaluación involucraría no sólo la generación de información desde una perspectiva longitudinal, sino además la incorporación de indicadores relativos a las dimensiones conceptuales del estatus social (i.e. la ocupación con su prestigio e ingresos asociados, el consumo y las formas de vida y prestigio que de él derivan, así como el acceso al poder y a los mecanismos que éste posee dentro de su estructura), de tal forma que resultase factible identificar, tanto los estratos de origen como los procesos de movilidad social.

Sin embargo, ante la imposibilidad de cubrir los requisitos planteados por dicho procedimiento, dado el tipo y las características de las fuentes de información disponibles (i. e. encuestas demográficas de corte transversal), consideramos que resulta pertinente recurrir a la variable del ingreso monetario mensual del grupo doméstico, para utilizarla como un indicador -poco refinado, pero indicativo a fin de cuentas- del estrato social relativo en el que los grupos domésticos pueden ser catalogados.

Al respecto, la información presentada en el segundo panel del cuadro 6 permite distinguir al menos tres rasgos importantes para nuestros propósitos. El primero consiste en el hecho de que las tres categorías de grupos domésticos que cuentan con algún miembro con condición migratoria que le permite laborar legalmente en Estados Unidos (i.e. grupos con rodinos, con tarjetas verdes y(o) con ciudadanos estadunidenses, presentan medias de ingreso mensual que son superiores a las correspondientes a los grupos domésticos sin migrantes tanto en el total como para los hogares jefaturados por hombres o mujeres. 6

En el interior de ese conjunto de grupos con mayores ingresos, destaca como segundo rasgo el que los grupos domésticos con rodinos presenten las medias de ingreso mensual más bajas. Este hecho, sin embargo, resulta consistente con las características observadas en los grupos domésticos con rodinos en relación tanto a sus altos índices de dependencia infantil, como a las ba-

${ }^{6}$ Las medias del ingreso mensual son estadísticamente diferentes entre los cuatro grupos incluidos, con un nivel de significancia de $\mathbf{0 . 0 5}$. 


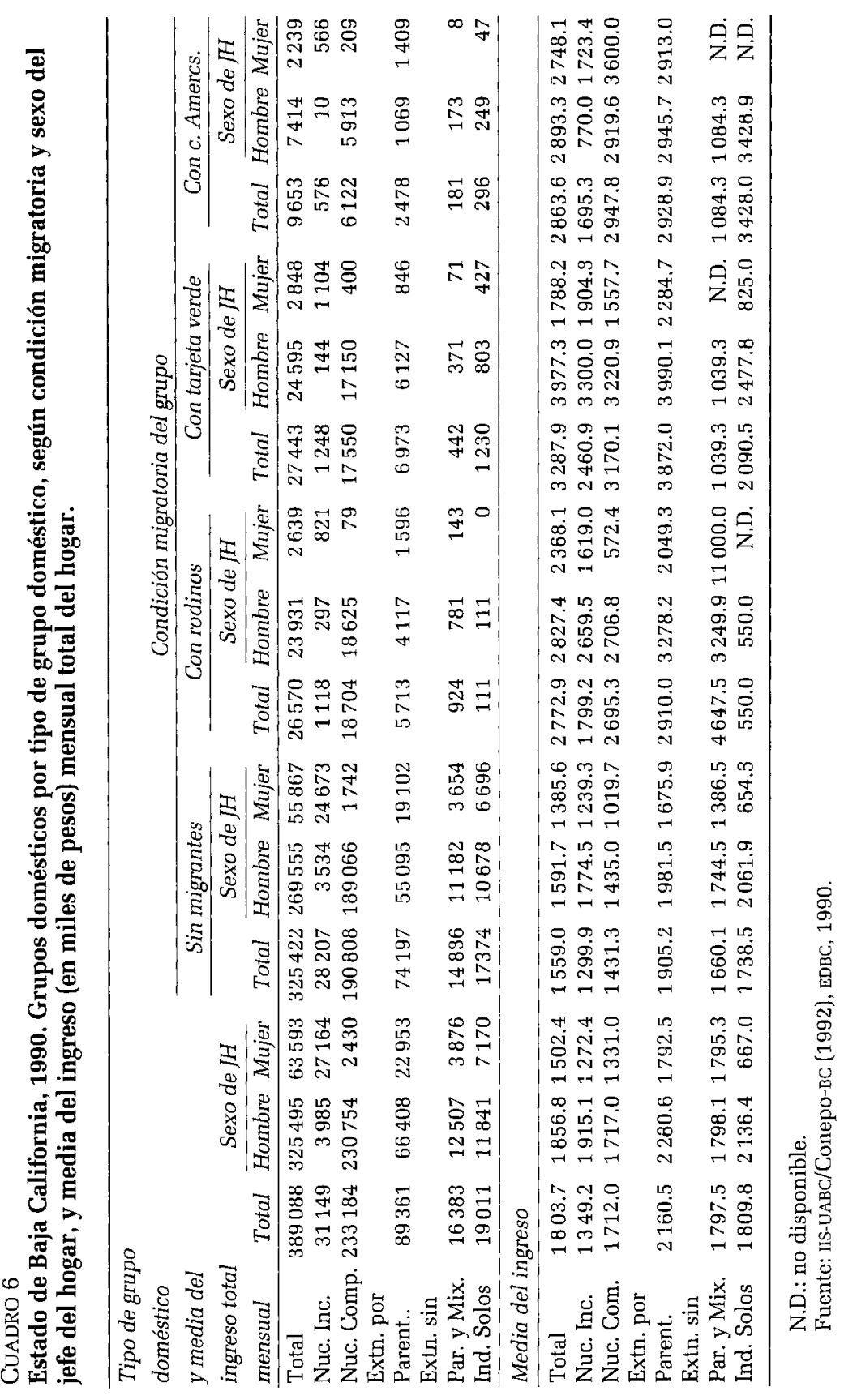


jas proporciones de miembros en edades activas con las que cuentan.

Los dos rasgos anteriores se complementan, finalmente, por el hecho de que los grupos domésticos con rodinos superan el ingreso mensual total de los grupos domésticos sin migrantes en todos los tipos de grupos considerados, con excepción de los hogares integrados por individuos solos. En el nivel del total de grupos domésticos con rodinos y sin migrantes, el diferencial de ingresos para los primeros es del orden de $77.9 \%$ en relación con el ingreso de los grupos sin migrantes, y de al menos $70 \%$ en el caso de los grupos jefaturados por mujeres. Es decir, en otros términos, que al nivel del total de grupos el ingreso de $10 \mathrm{gru}$ pos domésticos con rodinos, virtualmente equivale al de 18 grupos sin migrantes.

Estos elementos indicativos de una mejoría relativa en los ingresos de los grupos domésticos con rodinos, aunados a las características demográficas antes mencionadas, permiten sugerir -con las limitaciones del caso- que los grupos domésticos que recurrieron recientemente a la migración internacional legal, en apariencia han logrado establecer con éxito una estrategia de movilidad social ascendente.

Pasando a nuestro tercer supuesto general, por último, se debe señalar que se sugirió que resultaban previsibles modalidades diferenciales de recomposición -tanto cuantitativa como cualitativamente- del grupo commuters de Baja California, en función de efectos contextuales distintos originados a partir de la combinación del tipo (urbano-rural) de localidad de residencia, con las estructuras económicas que caracterizan tanto a cada uno de los municipios de la entidad, como a los dos condados colindantes con ellos en la frontera internacional entre México y Estados Unidos.

En este sentido, se identificó un marcado aumento entre 1986 y 1990 de los grupos domésticos que residen en localidades rurales y que cuentan con miembros que forman parte de los commuters, de los cuales un poco más de 5800 corresponden a grupos domésticos con rodinos residentes del medio rural. A la vez, se pudo observar un cambio en la concentración proporcional de grupos domésticos con commuters por municipios, en el que la participación del municipio de Mexicali aumentó de $41 \%$ en 1986 a más de $52 \%$ del total estatal en 1990 , al aglutinar a $63.6 \%$ del total estatal de los hogares que ahora cuentan con rodinos entre sus integrantes. En este nivel, además, se puso en evidencia un patrón divergente de selectividad por sexo del jefe del hogar, en el que mientras en Tijuana los hogares que incorporan rodinos entre sus miembros eran jefaturados por mujeres en $18 \%$ de los 
casos, en Mexicali la cifra correspondiente indica que sólo $6 \%$ de los hogares con rodinos están jefaturados por mujeres en este municipio.

Por otra parte, en el modelo de interacción de factores de los tres niveles de análisis, se observó que la variable contextual del municipio de residencia resultó ser la que generó los efectos de mayor magnitud, permitiendo identificar un patrón en el que -para todas las categorías comparables- los grupos domésticos del municipio de Mexicali presentan las más altas probabilidades de contar con rodinos.

El conjunto de elementos de selectividad diferencial a partir de los diversos rasgos de ubicación de los grupos domésticos con rodinos, en nuestra opinión, permite corroborar el supuesto de que al combinarse las condiciones estructurales de las economías de cada uno de los cuatro municipios de la entidad y de los condados colindantes con ellos en la frontera internacional, con los perfiles socioeconómicos que se definen a partir del tipo de localidad de residencia, se generarían, efectos contextuales que se traducirían en distintas formas de recomposición cuantitativa y cualitativa del grupo de commuters de Baja California.

Ante tal recomposición, un último objetivo a lograr en este estudio consiste en la identificación de programas y acciones que permitan mejorar las condiciones en las que desarrollan sus actividades los grupos domésticos que participan en la migración internacional a través de los rodinos. En este sentido, los resultados que se han obtenido nos permiten sugerir cinco rubros generales en los que se podrían llevar a cabo actividades con ese propósito.

\section{Asesoría Legal sobre Migración}

En este documento se describieron algunas de las características específicas con que surgen los programas de "Trabajadores Agrícolas Especiales" que dieron origen al grupo de los ahora denominados "rodinos". Estos programas, así como sus acciones complementarias, tienen un sustrato legal que, dado su carácter innovador -al crear nuevas categorías migratorias como los "extranjeros residentes temporales"- resultan virtualmente indescifrables, salvo para los expertos en la materia.

Aun logrando esclarecer el aspecto estrictamente legal de esos programas, quienes se ven involucrados en ellos enfrentan, además, la complejidad de los procedimientos que se han diseñado para operacionalizar administrativamente las disposiciones legales por parte de las autoridades de migración de Estados Unidos. 
El grado de dificultad que implican tanto el aspecto legal como el administrativo de estas nuevas modalidades de migración, han dado lugar a serios malentendidos y hasta a abusos por parte de prestadores de servicios. Al respecto, para presentar sólo un ejemplo, se debe mencionar que en conversaciones directas con rodinos se ha detectado la noción entre ellos de que su autorización para laborar en Estados Unidos es exclusivamente aplicable a las actividades agrícolas, noción que desde luego es legalmente infundada.

Estas formas de irregularidades, por desconocimiento o por engaño, podrían ser al menos limitadas a través de un programa de asesoría sobre disposiciones legales y trámites administrativos relativos a esta forma de migración.

\section{Asesoría sobre derechos en México}

Otro rubro genérico en el que se requieren acciones orientadas a apoyar a los miembros del contingente de commuters de Baja California, es el concerniente a los servicios de orientación sobre derechos y responsabilidades legales de este grupo en México.

Un elemento que los recientes procesos electorales en la entidad pusieron al descubierto (agosto de 1992), consiste en la incertidumbre que parece prevalecer entre los commuters mexicanos de Baja California en relación con su estatus jurídico en nuestro país. Durante ese periodo, miembros de ese grupo manifestaron dudas sobre sus derechos a ser incluidos en el nuevo padrón estatal de electores; a votar y ser votados, así como en torno a si su participación en esos procesos podría tener consecuencias no deseadas sobre su condición de "residentes temporales" de Estados Unidos, al ser identificados como no-residentes de ese país. De igual forma, el grupo de commuters en general y el de rodinos en particular, se han visto colocados en dilemas sobre cómo actuar en materias como la de su responsabilidad fiscal ante las autoridades de ambos países.

La condición legal de "residente temporal" en el extranjero que caracteriza a los miembros de este grupo, también ha creado incertidumbre en relación con sus derechos a tener propiedades inmuebles o bienes raíces en la zona fronteriza y en las costas de Baja California. Esta situación se deriva del hecho de que la legislación mexicana prohibe a los extranjeros adquirir ese tipo de bienes en esta zona del país y de que, en lo general, una amplia parte de ese grupo considera que ha perdido o renunciado a la nacionalidad mexicana, con lo que se autoexcluyen, por ejemplo, de los 
mecanismos de financiamiento que ofrece la banca mexicana para la adquisición de esos bienes. Las dos situaciones antes descritas, señalan la necesidad de acciones de asesoría que permitan que el grupo de rodinos identifique claramente tanto sus derechos como sus obligaciones, entre otras, en materia electoral, fiscal y de tenencia de la tierra en México.

\section{Capacitación laboral}

La tercer área general en la que se pueden diseñar programas y proyectar acciones que beneficien a estos grupos de transmigrantes, es la relacionada con el reconocimiento e incremento de su capacitación para las actividades productivas.

En este sentido se debe advertir que, a casi tres años de haberse iniciado el reclutamiento de este nuevo grupo de migrantes, para 1990 aún se percibe una concentración de más de $30 \%$ de sus miembros en actividades agropecuarias, en las que por sus requerimientos intrínsecos cabe suponer que se están subempleando las capacidades laborales que se detectan en los niveles de escolaridad de quienes se incorporaron al contingente de rodinos.

La subutilización de dichas capacidades, desde nuestra perspectiva, pudiera estar determinada entre otros motivos, por dos factores limitantes. El primero consiste en la "barrera natural" que impone la falta de dominio del lenguaje del país en el que se labora, al impedir el acceso a actividades que demanden habilidades más allá de las exclusivamente manuales.

El segundo factor que limita la plena utilización de las propias capacidades de este grupo, radica en los requerimientos técnico-académicos que sus integrantes tendrían que cumplir en Estados Unidos, para poder ejercer los oficios o profesiones en las que fueron instruidos.

Un programa diseñado para minimizar los efectos de esos dos factores limitantes de la diversificación y movilidad laboral ascendentes de los integrantes del grupo de rodinos, requeriría incorporar de manera inicial acciones tendientes tanto a la evaluación de los niveles de dominio de la lengua inglesa que prevalecen entre los rodinos, como a la identificación específica de los oficios y profesiones con que cuenta este grupo de migrantes.

A partir de ese diagnóstico inicial, por una parte, el siguiente objetivo a lograr en este tipo de programa consistiría en la organización de cursos que permitan elevar el dominio del inglés y(o) paralelamente, en la identificación de instituciones oficiales y organismos no gubernamentales que proporcionan ese tipo de servi- 
cio sin costo para las minorías en Estados Unidos. Por otra parte, también sería necesario identificar tanto los procedimientos como las instancias colegiadas, académicas o de entrenamiento, a través de las cuales se puedan acreditar, revalidar o certificar en Estados Unidos las habilidades con las que cuentan los rodinos. Este tipo de acciones permitiría que los migrantes commuters utilizaran en mayor medida sus capacidades hasta ahora subempleadas, potenciando con ello sus posibilidades laborales y salariales de movilidad ascendente.

\section{Servicios de atención a la salud y asistenciales}

El cuarto rubro general de acciones a desarrollar en relación con los commuters mexicanos de Baja California, estaría orientado a la adecuación, más que a la creación, de un programa que ya se encuentra en operación, a través del Instituto Mexicano del Seguro Social (IMSS).

Los grupos domésticos con rodinos, presentan características que delimitan un perfil en el que predomina una ubicación mayoritaria en las etapas tempranas del ciclo vital de los hogares; nivel elevado de sus índices de dependencia infantil; baja proporción de integrantes en edades activas y bajos índices de dependencia adulta, que al acompañarse de un número reducido de integrantes generan las más altas probabilidades para que un grupo doméstico cuente con rodinos.

La combinación de ese perfil de una etapa del ciclo vital de alta dependencia -que se ha identificado como la más propicia para la utilización del recurso de la migración internacional como parte de la estrategia de sobrevivencia de los grupos domésticos (Massey, 1987: 1 375)- con la carencia de atención a la salud en México por no laborar en el país, plantea la necesidad de acceso a servicios médico-asistenciales que hagan efectivo el derecho a la salud de los integrantes de los grupos domésticos con rodinos, a la vez que permitan la incorporación a las actividades productivas remuneradas de quienes están en posibilidad de realizarlas.

En este sentido, se debe advertir que el gobierno federal mexicano ha respondido a las demandas de los compatriotas que, laborando en Estados Unidos temporal o permanentemente, han formulado en materia de atención a la salud para ellos y para sus familiares que residen en México. La respuesta a esta demanda se instrumentó a través del IMSS, el cual, además de proporcionar servicios médicos por medio de un seguro facultativo con costo 
anual cubierto por el trabajador, incluye actividades culturales a realizar en el extranjero.

Esos objetivos, así como la promoción que se ha hecho del programa de seguro facultativo, permiten advertir que se ha orientado hacia quienes salen del país por temporadas más o menos prolongadas, a la vez que se excluyen de los servicios prestados los correspondientes a la atención de infantes por medio de las guarderías del sistema del IMSS.

A nivel de la frontera norte de México, este programa del IMSS debiera incluir de manera específica -tanto en su promoción como en sus acciones- a los nacionales que forman parte del grupo de commuters, puesto que aunque éstos no abandonan el país más que durante su jornada diaria de trabajo, también ellos y sus familiares se encuentran desprotegidos en materia de servicios médicos socialmente ofertados. Más aún, si este programa se ampliase para incluir servicios asistenciales como los de guardería, abriría la posibilidad para que miembros de los grupos domésticos con commuters se incorporaran a las actividades productivas y en consecuencia, en gran parte de los casos, se generara una aportación múltiple al IMSS.

Las actividades de gestoría que es necesario realizar ante las autoridades competentes para que el programa en cuestión se amplíe en los términos mencionados, podrían ser incluidas dentro de los planes de acción de las directivas de las asociaciones de "emigrados" que se han formado en las ciudades de la frontera norte de México. Este tipo de grupos "gremiales" cuenta con experiencias -más o menos exitosas- en procesos de salvaguarda de los intereses de los commuters mexicanos (e.g. en materia de tenencia de vehículos), y a la vez sostiene nexos estrechos con agrupaciones de trabajadores de origen mexicano en Estados Unidos (e.g. United Farm Workers of America, fundada por César Chávez), que ya han demostrado su capacidad de negociación con el gobierno federal mexicano.

\section{Repatriación laboral}

El quinto rubro general de acciones susceptibles de ser aplicadas para mejorar las condiciones de los grupos domésticos que cuentan con rodinos, se relaciona con aquellas actividades que se pueden orientar para lograr que personas con altos niveles de preparación se reintegren a desarrollar sus actividades productivas en México.

En ese sentido se debe partir de la consideración de que, aunada a su formación lograda en México, quienes participan en los mercados internacionalizados de trabajo han adquirido experien- 
cias adicionales en áreas de organización, administración y formas de operación, tanto de procesos productivos como en la comercialización y en la prestación de servicios. En un contexto de apertura rápida y creciente de los mercados internacionales, quienes cuentan con formación y experiencias de esa naturaleza, bien pueden ser considerados como agentes potencialmente generadores de las nuevas formas de organización productiva, de intercambio y servicios que las condiciones de apertura demandarán -de manera particular y creciente- en la frontera norte de México.

La reincorporación laboral a México de quienes cuentan con esas características de formación y experiencia ampliada, operativamente no debe plantearse como un retorno a un empleo nominal dadas las diferencias en las estructuras salariales de ambos países. En su lugar, se requiere de un programa que fomente la reincorporación de esas personas a través de su participación en la apertura de nuevas fuentes de empleo.

Un programa con ese objetivo demandaría incorporar acciones que permitan ofrecer, entre otros, procedimientos de financiamiento en condiciones preferenciales; mecanismos para la instalación de organizaciones a partir de esquemas de riesgo compartido; ambientes de coexistencia y escalados para la etapa de arranque de las organizaciones (e.g. "incubadoras de empresas") e incentivos fiscales en los periodos iniciales.

Ese tipo de requerimientos delinean un perfil de organismo adecuado, para el diseño e implantación de un programa con esas características; dependencias gubernamentales de nivel estatal como las secretarías de fomento o desarrollo económico son candidatos viables para su promoción y administración. Esas áreas de actividad de los gobiernos estatales se caracterizan por contar con acervos de información, indispensables para la identificación de proyectos necesarios y viables, así como con las instancias de gestión necesarias para la operación financiera de un programa como el que se propone, cuyo objetivo último sería el de recuperar parte del capital humano que México ha perdido con la migración de los rodinos.

\section{Bibliografía}

Acuña, G. Beatriz (1983), "Migración y fuerza de trabajo en la Frontera Norte de México", Revista de Estudios Fronterizos, año I, núm. 2, septiembre-diciembre, pp. 13-57.

Aldrich, H.J. y F. D. Nelson (1984), Linear probability, logit and probit models, Beverly Hills, Sage Publications, Series: Quantitative Applications in the Social Sciences, núm. 45, $94 \mathrm{pp}$. 
Alegría, Tito (1990), "Ciudad y transmigración en la Frontera de México con Estados Unidos", Frontera Norte, vol. 2, núm. 4, Tijuana, El Colegio de la Frontera Norte, julio-diciembre, pp. 7-38.

Arámburo, V. Guillermo y L. Fidel Fuentes Fidel (1992), “Transmigración legal. Los Tarjetas verdes en la frontera México-Estados Unidos. Reporte Terminal de Investigación", Mexicali, Instituto de Investigaciones Sociales-Facultad de Economía-Universidad Autónoma de Baja California (mimeo.), $144 \mathrm{pp}$.

Bilsborrow, R.E. et al. (1987), "The Impact of Origin Community Characteristics on Rural-Urban Out-Migration in a Developing Country", en Demography, vol. 24, núm. 2, pp. 191-210.

Briggs, M. Vernon Jr. (1986), "The 'Albatross' of Immigration Reform: Temporary Worker Policy in the United States", International Migration Review, vol. 20, núm. 4, pp. 995-1019.

Estrella, Gabriel (1991), "Fertility and Migration: a proximate determinants analysis in the case of Baja California", México, tesis de doctorado, Londres, London School of Economics (mimeo.), $272 \mathrm{pp}$.

(1992), "Grupo doméstico, crisis y migración internacional. Reporte final de investigación", Mexicali, AMEP/Instituto de Investigaciones Sociales-Universidad Autónoma de Baja California (mimeo.), 218 pp.

Findley, Sally E. (1987), Rural Development and Migration. A study of family choices in the Philippines, Boulder and London, Westview Press, $308 \mathrm{pp}$.

García, B., H. Muñoz y O. de Oliveira (1982), Hogares y trabajadores en la ciudad de México, México, El Colegio de México-unam, pp. 202.

García, M. Jorge (1992), "Configuración económica de Baja California", Revista de Estudios Fronterizos, núms. 27-28, enero-abril/mayo, Mexicali, Instituto de Investigaciones Sociales-Universidad Autónoma de Baja California, pp. 29-76.

García y Griego, Manuel y C. Ménica Verea (1988), México y Estados Unidos frente a la migración de los indocumentados, México, Miguel Ángel Porrúa/Coordinación de Humanidades-UnaM, 176 pp. (Las Ciencias Sociales).

IIS-UABC/COnEpo-BC (1987), "Encuesta Demográfica de Baja California 1986. Resultados", Mexicali, ConEPo-BC.

—_(1993), "Encuesta Demográfica de Baja California 1990”, Mexicali, IIS-UABC (en prensa).

Knoke, D. y P. Burke (1980), Log-linear models, Beverly Hills, Sage Publications, Series: Quantitative Applications in the Social Sciences, núm. 20, pp. 80.

Lauby, J. y O. Stark (1988), "Individual Migration as a Family Strategy: Young Women in the Philippines", Population Studies, vol. 42, Londres, pp. 473-486.

Lipton, Michael (1982), "Migration from rural areas of poor countries: The impact of rural productivity and income distribution", en R.H. Sabot (comp.), Migration and the Labor Market in Developing Countries, Boulder, Westview Press, pp. 191-228. 
Massey, Douglas S. (1987), "Understanding Mexican Migration to the United States", American Journal of Sociology, vol. 92, núm. 6, The University of Chicago, pp. 1372-1403.

Margulis, Mario (1989), "Reproducción de la unidad doméstica, fuerza de trabajo y relaciones de producción", O. de Oliveira et al. (comps.), Grupos domésticos y reproducción cotidiana, México, UNAM/EI Colegio de México/Miguel Angel Porrúa, pp. 189-215.

Nelson, Eric R. (1976), "African Rural-Urban Migration: Economic Choice Theory and Kinshasa Evidence", tesis doctoral, Yale University (mimeo.).

North, F. Davis y F. Marion Houston (1976), The Characteristics and Role of Ilegal Aliens in the U.S. Labor Market: An Exploratory Study, Washington, D.C. Linton y Company.

Oliveira O. de y V. Salles (1989), "Introducción" en O. de Oliveira et al. (comps.), Grupos domésticos y reproducción cotidiana, México, UNAM/El Colegio de México/Miguel Ángel Porrúa, pp. 9-36.

Pessar, Patricia (1982), "The Role of Households in International Migration and the case of U.S. -Bound Migration from the Dominican Republic", International Migration Review, vol. 16, núm. 2, pp. 342-364.

Roberts, Kenneth D. (1982), "Agrarian structure and labor mobility in rural Mexico", Population and Development Review, vol. 8, núm. 2, pp. 299-322.

Root, B.D. y G. F. DeJong (1991), "Family Migration in a Developing Country", Population Studies, vol. 45, núm. 2, Londres, pp. 221-233.

Shryock, H. et al. (1976), The Methods and Materials of Demography, Nueva York, Academic Press, edición condensada, pp. 577.

Stark, Oded (1982), "Rural-to-urban migration and intrafamilial risk-trading agreements in LDCs", ponencia presentada en la reunión Anual de la Population Association of America (mimeo.).

Sttoddard, R. Ellwyn (1989), "Amnesty: Functional Modifications of a Congressional Mandate", Journal of Borderlands Studies, vol. 4, núm. 2, pp. 26-58.

Thadani, Veena (1985), "Social relations and geographic mobility: Male and female migration in Kenya", Guy Standing (comp.), Labour Circulation and the Labour Process, Londres, Croom Helm, pp. 182-218.

Torrado, S. (1986), "Cuestiones metodológicas relativas a la investigación sociodemográfica basada en censos y encuestas en Hogares", R. Corona et al., Problemas metodológicos en la investigación sociodemográfica, México, Pispal- El Colegio de México, pp. 81-107.

Trager, Lilian (1984), "Family Strategies and the Migration of Women: Migrants to Dagupan City, Philippines", International Migration Review, vol. 18, núm. 4, pp. 1264-1277.

Verma, V. y M. Pearce (1986), CLUSTERS. A Package program for the Computation of Sampling Errors for Clustered Samples. Reference Manual, International Statistical Institute, Research Centre, Voorburg, Netherlands, versión $3.0,88 \mathrm{pp}$.

Wood, Ch. H. (1982), "Equilibrium and Historical-Structural Perspectives on Migration”, International Migration Review, vol. 16, núm. 2, pp. 298319. 


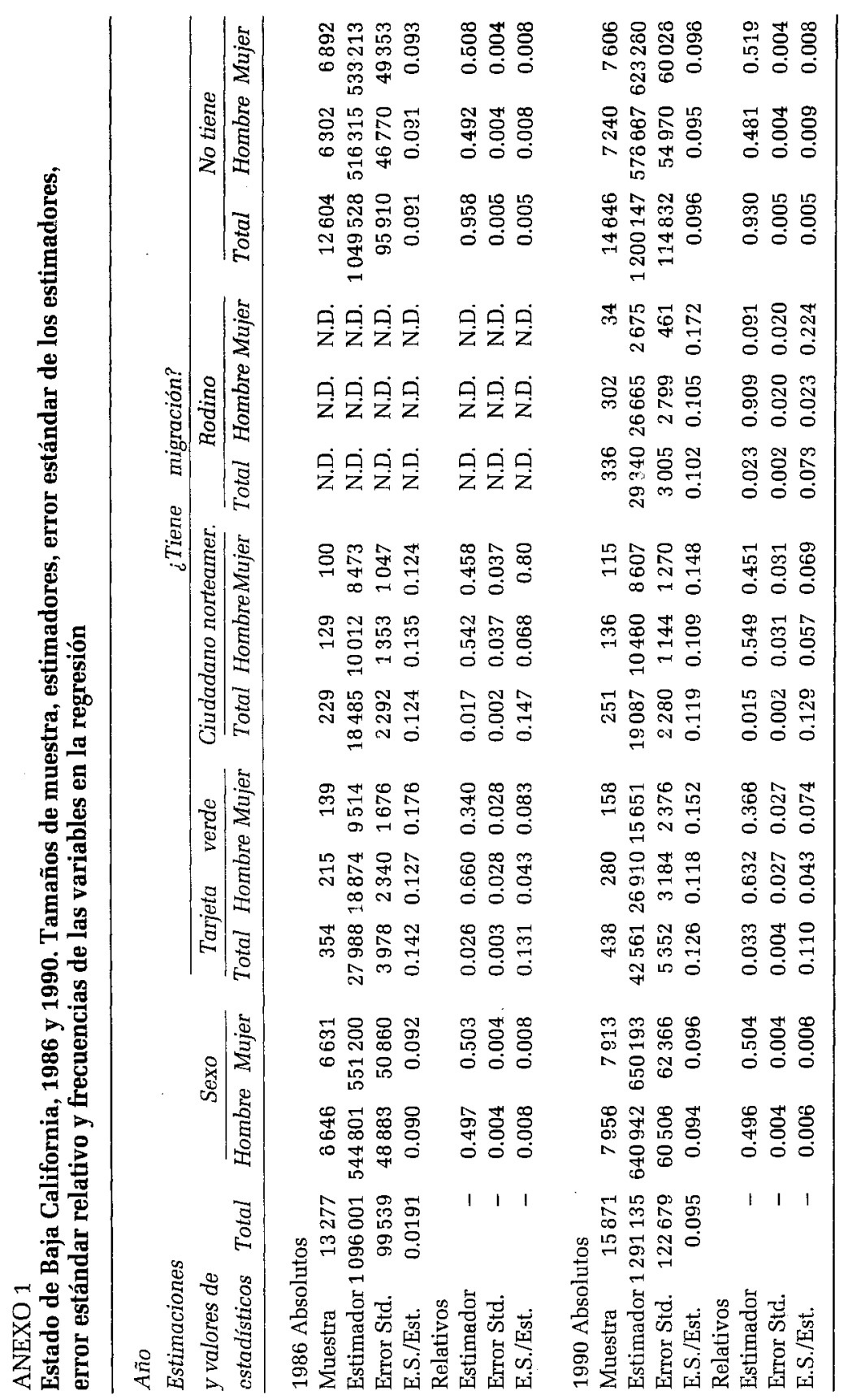


